\title{
EVALUATION OF OPERATIONS FOR RELIEF OF PAIN*
}

\author{
James C. White, M.D.
}

\section{INTRODUCTION}

Neurosurgical attempts to relieve persistent pain of intolerable intensity date back to the closing years of the last century, so that a neurosurgeon like myself approaching 70 has had the challenge of working in this field for over half its period of development. The standard operations for relief of pain, which are to be evaluated in this lecture, have been under trial for an ample period to appraise their end results. Retrogasserian and posterior spinal rhizotomies, anterolateral cordotomy, and sympathectomy for visceral pain were developed by Frazier, Labbé, Spiller and Martin in this country, and by Jonnesco in Romania and Leriche in France in the first quarter of this century.

Curious as it may seem, in all the articles that have becn published about these procedures few have been concerned with late results. Yet the nervous system, given time, has a singular ability to recover its function, even though its sensory fibres are supposed to be incapable of regeneration when they have been severed within the dura, where the axons are not provided with sheaths of Schwann. The incidence of late return of pain, which is so important when the sufferer does not have malignant disease and is not limited to a very brief survival, is a subject that has been of increasing concern to me and my colleague, Dr. W. H. Sweet, since we published our monograph on pain in 1955 .

Thanks to the generosity of my associates at the Massachusetts General Hospital in allowing me to review their cases, I have been able to follow a large proportion of our 665 patients who suffered persistent pain of such unbearable intensity that relief by interruption of sensory pathways was mandatory to prevent narcotic addiction and deterioration of morale. It is these statistics that I am going to review.

\section{Section of Cranial Sensory Nerves and Tracts}

1. Retrogasserian Rhizotomy: When the trigeminal sensory rootlets are cut

\footnotetext{
* From the Neurosurgical Service, Massachusetts General Hospital and Department of Surgery, Harvard Medical School, Boston, Massachusetts.

To be presented before the Japan Neurosurgical Society, October, 1962.
} 
behind the Gasserian ganglion return of sensation to the de-afferentiated portion of the face and oral cavity may occur. Recurrence of pain may be related to overlap from remaining intact fibres, if only a selective root section is carried out, or to the proximity of the surgeon's transection to the sensory nerve cells in the ganglion. If a few of these are left connected by their central axons to the pons and descending trigeminal root, peripheral regeneration will take place, as is invariably the case after mandibular or maxillary neurotomy. With the subtemporal approach return of sensation is not a rarity. According to Bakay's statistics, published in my monograph with Sweet (White and Sweet, 1955), this has occurred in $13.6 \%$ of our series of 250 patients operated upon between 1937 and 1947. In the hands of other neurosurgeons the recurrence rate has varied from 3\% in Craig's series (1941) to $14.1 \%$ in that of Peet and Schneider (1952). Statistics from five other clinics for comparison with ours are given in Table 1 .

Table 1. Incidence of recurrent trigeminal neuralgia following retrogasserian rhizotomy by temporal subdural approach

\begin{tabular}{lc}
\hline Grant (1938) & $5.4 \%$ \\
Craig (1941) & 3.0 \\
Guidetti (Olivecrona clinic) (1950) & 8.3 \\
Peet and Schneider (1952) & 14.1 \\
Stookey and Ransohoff (1959) & 7.0 \\
Massachusetts General Hospital series 1937-47 & \\
$\quad$ (collected by Bakay and reported by White & 13.6 \\
\hline
\end{tabular}

If the modifications of Taarnh $\phi \mathrm{j}$ (1952) or Pudenz and Shelden (1952) are used, in which the Gasserian root is decompressed or its fibres compressed, recurrence of neuralgia is much more frequent. Because of this we have not often employed this procedure, but it has been reported to be as high as $83 \%$ in the hands of Northfield (1961).

When the entire Gasserian root is cut as it leaves the pons recurrence should be nil, but we have not carried this out by Dandy's approach through the posterior fossa in a sufficient number of long survival cases with tic douloureux to confirm this statement. The only available statistics on an impressive series (145) are those reported by Guidetti (1950) from Olivecrona's clinic in Stockholm. As Olivercrona for the most part carried out only fractional transection in order not to produce total anaesthesia of the face, his rate of recurrence of trigeminal neuralgia has been $17.9 \%$, but in response to a recent inquiry he (personal communication) reports that he has never seen recovery when the entire root has been cut.

The statistical incidence of the major complications after the subtemporal operation are summarized in Table 2 . On our service, where approximately half of these operations are carried out by the residents, the mortality rate has been $1.6 \%$. This compares favourably with that of other leading clinics. The other 
Table 2. Complications following retrogasserian rhizotomy for trigeminal neuralgia

\begin{tabular}{|c|c|c|c|c|c|c|c|}
\hline & $\begin{array}{l}\text { Total } \\
\text { No. } \\
\text { Pts. }\end{array}$ & $\begin{array}{l}\text { Opera- } \\
\text { tive } \\
\text { Mor- } \\
\text { tality }\end{array}$ & $\begin{array}{c}\text { Kera- } \\
\text { titis }\end{array}$ & $\begin{array}{c}\text { Transi- } \\
\text { tory } \\
\text { Facial } \\
\text { Paralysis }\end{array}$ & $\begin{array}{c}\text { Perma- } \\
\text { nent } \\
\text { Facial } \\
\text { Paralysis }\end{array}$ & $\underset{\text { Palsy }}{\text { Ocular }}$ & $\begin{array}{l}\text { Post- } \\
\text { op. } \\
\text { Paraes- } \\
\text { thesia }\end{array}$ \\
\hline Sachs (1935) & 182 & $2.3 \%$ & $7.7 \%$ & $9.9 \%$ & & & \\
\hline Grant (1938) & 925 & 1.4 & 9.0 & 3.4 & $0.7 \%$ & $1.1 \%$ & $3.4 \%$ \\
\hline Craig (1941) & 434 & 1.9 & 1.1 & & & & \\
\hline Guidetti (Olivecrona clinic) (1950) & 515 & 0.8 & & & 1.6 & & 3.1 \\
\hline Peet and Schneider (1952) & 544 & 1.6 & 15.1 & 6.5 & & & 0.4 \\
\hline Stookey and Ransohoff (1959) & 656 & 0.8 & 1.0 & 7.8 & 1.0 & & 10.0 \\
\hline $\begin{array}{l}\text { Massachusetts General Hospital } \\
\text { series } 1937-47 \text { (collected by } \\
\text { Bakay and reported by White } \\
\text { and Sweet, 1955) }\end{array}$ & 250 & 1.6 & 4.4 & 4.0 & 1.6 & 1.6 & \\
\hline
\end{tabular}

Tic was bilateral in 0.8 of our cases and ranged from $1.8 \%$ to $5.9 \%$ in the other series.

major complications were facial paresis, $4.4 \%$, which disappeared within a year in all but $1.6 \%$; paralysis of extra-ocular muscles in $1.6 \%$; and corneal ulceration in $4.4 \%$. The complication most to be dreaded, which is of similar concern after anterolateral cordotomy, is disagreeable paraesthesia of the anaesthetic portion of the face. This developed in a slightly over $3 \%$ of the 1440 patients followed by Grant and by Guidetti. The one advantage of root compression or fractional section of the trigeminal root as it leaves the pons is the fact that they rarely, if ever, produce disagreeable paraesthesia.

2. Section of Other Sensory Cranial Nerves: How often posterior lingual and upper pharyngeal sensibility recovers after cutting the glossopharyngeal root is difficult to document. We are not yet certain of the extent of overlap from sensory fibres in the upper vagal rootlets and therefore generally sacrificed the most rostral rootlet or two in our operations for glossopharyngeal neuralgia. Pain has not recurred in our 10 cases followed up to seven years (Table $3 \mathrm{~A}$ ). One of my patients after section of the nervus intermedius, glossopharyngeal, and upper vagal rootlets for long-standing pain after mastoid surgery suffered recurrence of neuralgia in her ear four years after rhizotomy. This has since been relieved for seven years by section of the descending bulbar trigeminal tract (Table $3 \mathrm{~B}$ ).

The posterior fossa approach for cutting the fifth and ninth nerves, with additional upper cervical rhizotomy, for pain in carcinoma of the throat and neck was first advocated by Dandy (1929) and has been most extensively employed by Grant (1943) and Wetzel and Biddle (1959). While section of the fifth root alone, or the fifth and ninth combined, is generally successful in relieving pain in the face, tongue, and jaw, it often fails to relieve pain deep in the ear. The region of the ear is innervated not only by the trigeminus, glossopharyngeal, and upper cervical roots but also by the nervus intermedius (sensory branch of the facial) and the 
Table 3. Results of sensory rhizotomy of lower cranial nerves

A) IXth and upper fascicles of Xth in glossopharyngeal neuralgia:

10 cases relieved over periods up to $7 \mathrm{yrs}$.

0 recurrences

0 serious complications

B) IXth and upper Xth + nervus intermedius in post-mastoidectomy neuralgia:

1 case relieved for 4 yrs., then recurrence (relieved 7 yrs. following section of descending tract of $V$ th)

C) Vth, IXth and upper Xth with posterior roots of upper cervical plexus and various combinations of these procedures in carcinoma of oropharynx:

Only 9 of 19 cases benefitted, with 5 hospital deaths.

9 of 16 cases reported relieved with 3 hospital deaths by Wetzel and Biddle (1959).

vagus. While it is possible to identify and divide the former, wc have demonstrated by electrical stimulation that all the vagal rootlets can transmit pain and it is only possible to divide the upper two of this complex of four to five or more without paralyzing the muscles of deglutition and the vocal cord. In our hands transitory relief has been achieved for a few months in only 7 of 19 cases of carcinoma of the oropharynx, and 5 of this group of exceedingly poor risks died in the hospital. Wetzel and Biddle had 9 successes and 3 deaths in their 16 operations. Because of these disheartening experiences we are now exploring the effectiveness of stereotactic thalamotomy and the promising modifications of frontal leucotomy which have been proposed by Scarff (1950), Grantham and Spurling (1953), and White, Sweet, and Hackett (1960).

3. Medullary Tractotomy of Descending Trigeminal Root: This operation of Sjöqvist, as pointed out by Sweet (White and Sweet, 1955), Brodal (1959), and Kerr (1962), produces analgesia not only of the face, nasal cavity, and mouth but within the middle ear and pharynx, which are innervated by the nervus intermedius (the sensory root of the facial) and by the glossopharyngeal and vagus. After 12 bulbar tractotomies for tic douloureux reported by Sweet in our book (White and Sweet, 1955) analgesia has been present over three to six years, but numerous failures have been reported by others (see Table $4 \mathrm{~A}$ ). While the complication of facial paraesthesia is not reduced, we believe that this operation has a limited but definite place in the treatment of younger individuals with upper facial neuralgia in which the ophthalmic division must be sacrificed and in those who require a second operation for bilateral facial pain. As this tractotomy produces analgesia rather than anaesthesia, a foreign body can still be felt in the eye and postural as well as tactile sensibility of the lips, tongue, and jaw are preserved. Unfortunately pain in the mandibular division is likely to recur, as some of its fibres leave the descending root to enter the quintothalamic tract above the obex, and a rather high proportion of subjects complain of unpleasant paraesthesia afterwards. Kunc (1960) has recently shown that if the exposure is carried out under 
Table 4. Bulbar section of descending trigeminal tract below level of obex

A) In trigeminal neuralgia*

12 successful cases without recurrence-White and Sweet (1955) No deaths Analgesia maintained after 3 to 6 years.

6 successes with 2 failures at 6 months, but late recurrent pain in 1-Grant (1948)

124 cases with $37 \%$ rate of recurrence reported by Guidetti (1950) from Olivecrona's clinic.

35 cases with $21 \%$ recurrence and $5.7 \%$ postoperative mortality reported by Hamby et al. (1948)

Only 1 successful late result in 5 cases reported by Northfield (1961)

* This operation is suitable only for upper facial neuralgia in younger individuals in whom corneal sensation is important to preserve or when neuralgia is bilateral. It is not of ten successful in mandibular neuralgia, as some of the third division fibres leave the descending root above the level of the obex.

B) In malignancy of oropharynx

Patients with cervical node involvement had additional section of upper cervical posterior roots.

3 cases with early failure-White and Sweet (1955)

3 successful cases-Sjöqvist (1948)

5 successful results in 9 survivors-Grant and Weinberger (1941)

regional anaesthesia it is possible to localize the position of the three trigeminal divisions within the tract and also the fibres of nervus intermedius, glossopharyngeal, and vagus nerves by pricking the side of the medulla with a needle point. The latter lie most dorsally between the lateral border of the cuneate fasciculus and the mandibular division, while the ophthalmic division fibres are situated most ventrally at the edge of the spinothalamic tract and just above the outflow of the spinal accessory rootlets (Fig. 1).

Despite the extensive area in the face, mouth, nose, ear, and throat that receives its pain-conducting fibres via the descending trigeminal tract, medullary tractotomy in our experience has not proved to be a successful solution for relief of pain from cancer of the oropharynx, even if combined with division of the upper cervical sensory roots (Table 4B). In contrast to the encouraging report by Sjöqvist (1949) and 5 out of 9 cases of malignant pain in the face reported relieved by Grant and Weinberger (1941), our results have been most discouraging, even though post-mortem examination has shown complete transection of the entire descending radix in a subject whose pain had recurred before the fatal termination of his disease. The failure must be ascribed to fibres leaving the tract above the level of the obex to enter the bulbothalamic tract. It is unfortunate that the dorsolateral medulla cannot be incised above this level without leading to ipsilateral unsteadiness from damage to the inferior cerebellar peduncle and vestibular nuclei. 


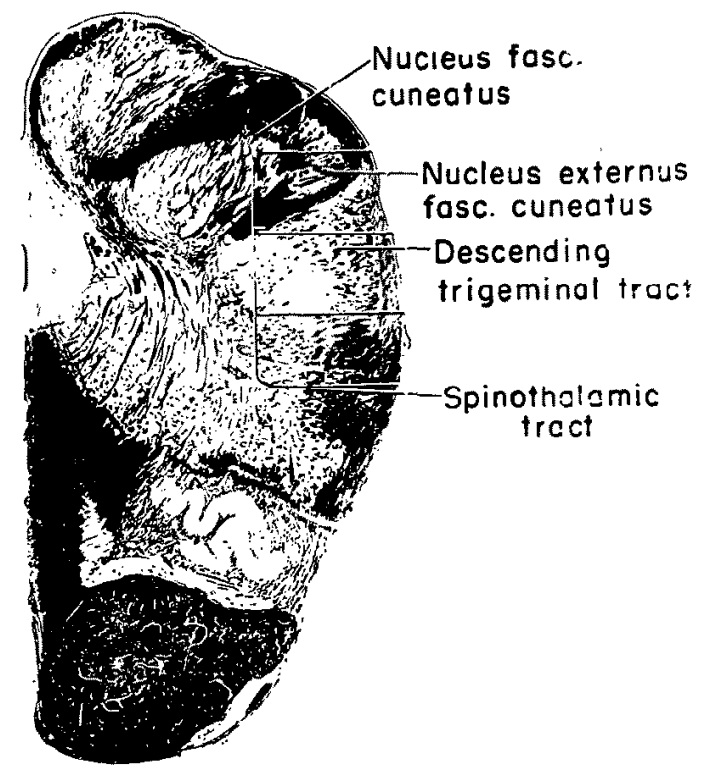

Figure 1, Anatomical relations of descending trigeminal tract in the medulla.

From Functional Neuroanatomy by W. J. S. Krieg, first edition, 1942, published by The Blakiston Company, Philadelphia, with the kind permission of the author.

\section{Section of Posterior Spinal Sensory Roots}

Sensory rhizotomy has very definite limitations. As pointed out so clearly by Nathan and Sears (1960), who have reviewed previous findings in animals by Sherrington and other early investigators and by Foerster in man, motor function is seriously impaired by loss of tactile and postural sensibility. This is especially true if the important sensory roots to the arm (C6 and C7), leg (L4-S2), or bladder (S2-S4) are sacrificed. Furthermore, as demonstrated by Foerster (1933) (Fig. 2), sensory root overlap in the thorax and abdominal dermatomes is so extensive that at least one if not two roots must often be cut above and below the inflow of an irritated spinal nerve in order to secure permanent relief. As will become apparent later, we have learned this from frustrating experiences in dealing with intercostal neuralgia, pain in operative incisions after repair of inguinal hernia, and removal of bone grafts from the iliac crest. It is, moreover, all too easy to miss tiny sensory rootlets unless the surgeon uses magnifying glasses to make certain that his rhizotomy is complete. If even a minute fibre or two are left pain will persist at its original intensity.

After four upper thoracic posterior roots have been cut anaesthesia may remain complete for twenty years, as is illustrated in Figure 3. On the other hand, when 


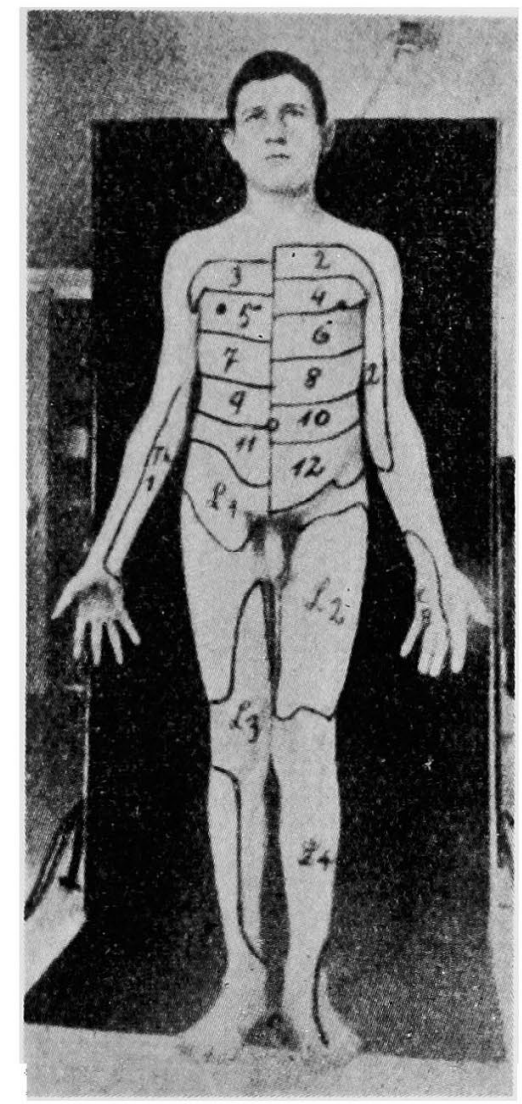

Figure 2. Cutaneous areas (dermatomes) supplied by spinal nerves.

From article by Forester in Brain, 1933, with permission of The Macmillan Co., London.

two posterior roots have been severed over a more limited area, such as from C8 to $\mathrm{T} 1$ or $\mathrm{T} 12$ to $\mathrm{L} 1$, to relieve pain in ulnar neuralgia and that following removal of bone from the iliac crest, we have seen it return within a few months, even when the cutaneous area originally involved has remained anaesthetic. The type of pain most effectively relieved by posterior rhizotomy is that caused by carcinoma involving the lymph nodes in the upper neck and angle of the jaw (Fig. 4), provided the neoplasm does not involve additional cranial nerves.

Table 5 summarizes the results of posterior rhizotomy at various levels for the relief of pain in carcinoma and other types of neuralgia. Inspection of these statistics, which go back to the beginning of my experience in the mid-thirties, shows the difficulties due to the variable and at times unbelievably extensive degree of sensory overlap. This does not apply so much to the superficial distribution of the classical dermatomes as to the underlying innervation of subcutaneous tissue, fascia, muscle, and bone. In pain from malignant involvement of the cervical nodes 7 patients were relieved by rhizotomy of the upper four or five sensory roots, but deep pain in the ear, oral or nasopharynx, and throat from involvement of 


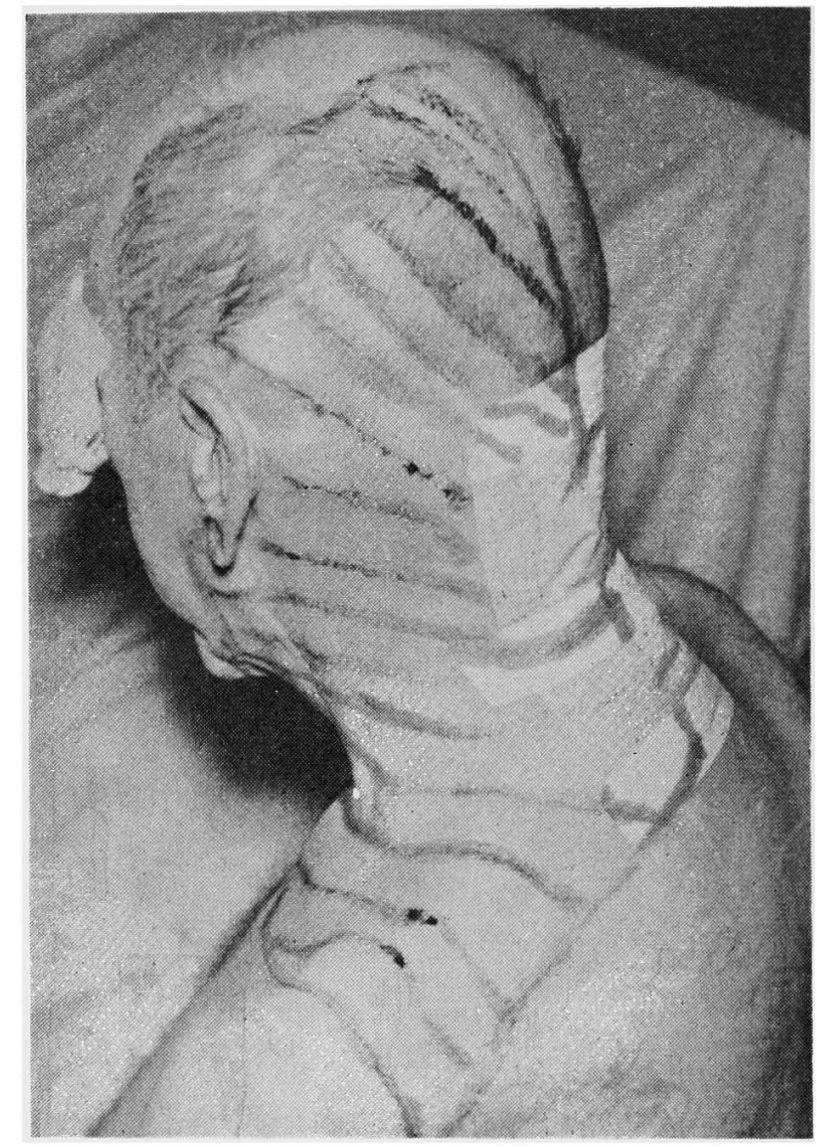

Figure 3. Relief of pain in carcinoma of tongue invading cervical nodes.

The upper four posterior cervical roots have been divided, with relief of pain to date (7 months).

cranial nerves accounted for failures in 6 others (Table 5A). The so-called myotomes and sclerotomes undoubtedly have a much wider derivation of sensory nerves than the overlying skin. This was brought home to me by futile attempts to relieve two women of pain after radical mammary resection (Table 5B). Each complained of persistent intense pain in the area from which the pectoral muscle had been dissected from the upper ribs. Posterior rhizotomy from T1 to T5 made this area superficially anaesthetic, but in no wise reduced their discomfort. Residual sensibility must have been mediated by the lateral anterior thoracic nerves, which descend from the brachial plexus to supply the pectoral muscles.

It has become clear that a few overlapping sensory axons from a root above or below the anaesthetic area may gradually reproduce the original complaints, 


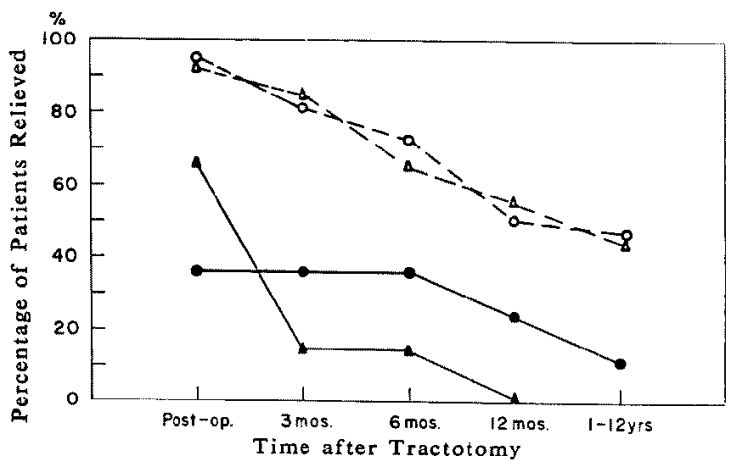

Figure 4. Duration of analgesia and relief of pain following anterolateral cordotomy for pain in non-malignant neuralgias.

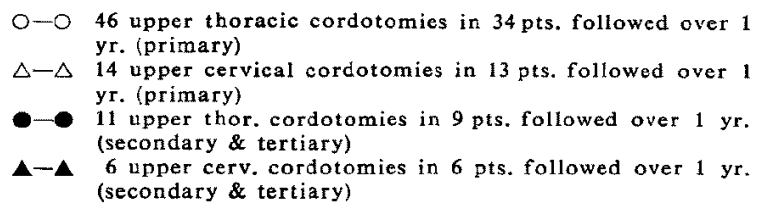

although several months may elapse before pain reappears. Furthermore, there is considerable variation in the extent of sensory overlap from one individual to the next. This means that section of a theoretically sufficient number of sensory roots will give permanent relief in some individuals, but will fail in others. The following examples will serve to back up this statement: Ulnar neuralgia from trauma to the nerve in its epicondylar groove was treated four times by posterior rhizotomy from $\mathrm{C} 8$ through $\mathrm{T} 2$ (Table $5 \mathrm{C}$ ). Three of these patients have maintained satisfactory relief from one to four years, but the fourth developed a recurrence within a few months. In 5 other individuals with neuralgia of the lateral femoral cutaneous nerve, neuralgia was due to a crushing injury to the thigh in 1 , injuries from surgical incisions in the lateral thigh in 2 , and in the course of lumbar sympathectomy in 2 other instances (Table $5 \mathrm{E}$ ). Section of the second third lumbar roots has resulted in prolonged relief (two to three years) in 3 , but with contraction of the anaesthetic area and return of dysaesthesia after five to twenty months in the other 2 . Here it was demonstrated by diagnostic block with xylocaine that the overlapping sensory fibres were located in the first lumbar and second sacral nerves. Again in 2 individuals with pain below the iliac crest following removal of bone for grafting, all discomfort has been relieved in 1 following section of the twelfth thoracic and first lumbar sensory roots, while the second, who experienced pain in an exactly similar area, continues to complain after additional rhizotomy of L2 and L3. Electrical stimulation by Dr. Sweet at the time of his second operation had shown the pain to come over these roots, but more recent diagnostic blocking of $\mathrm{T} 11$ with xylocaine has demonstrated that this root also supplies fibres to the 
Table 5. Results after section of posterior spinal roots-40 cases

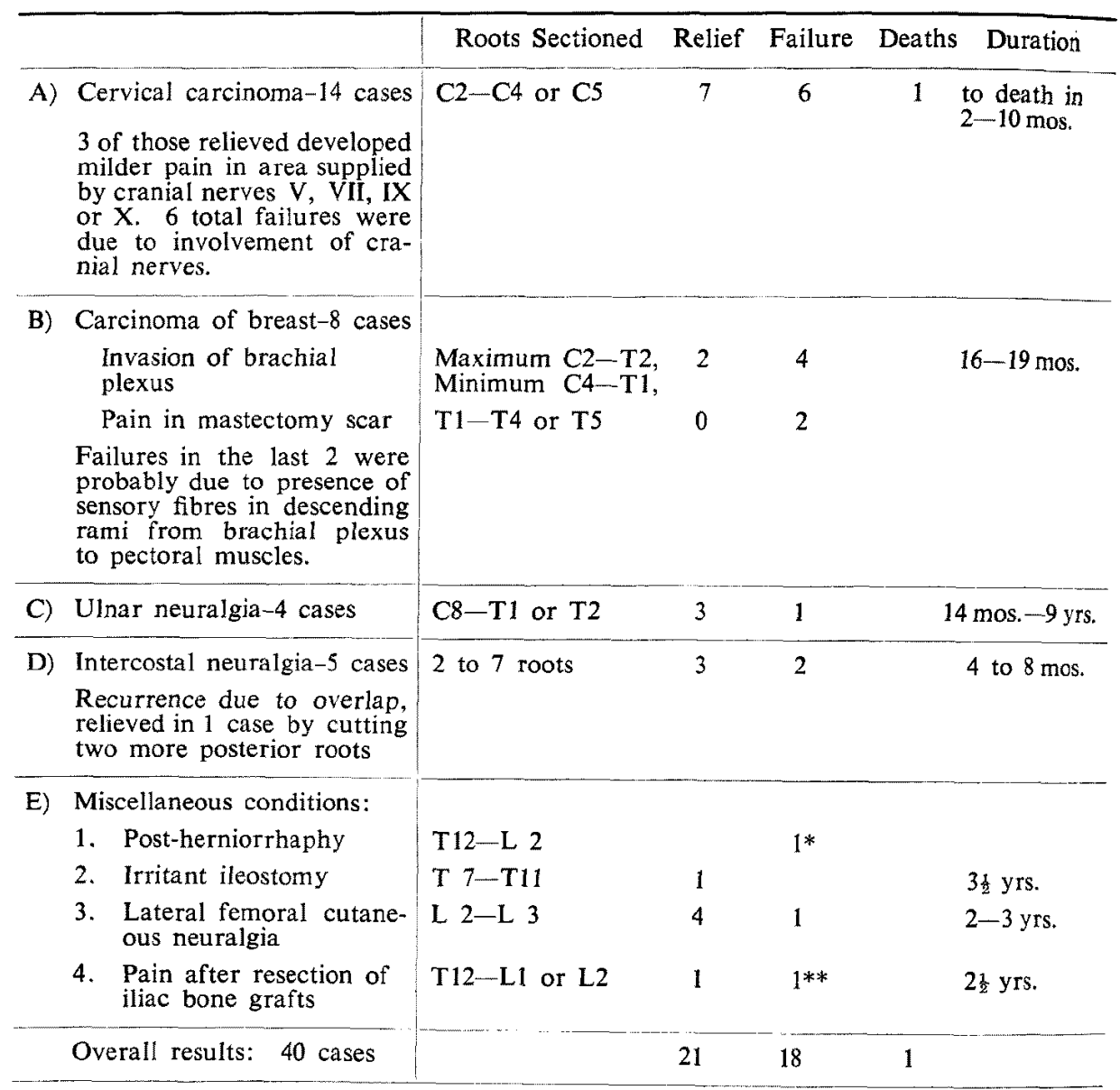

* Failure probably due to overlap from $\mathrm{T} 11$,

** Failure proved by subsequent nerve block to be due to overlap from T11.

sensitive scar.

To counterbalance a $50 \%$ incidence of failure it must be emphasized that this high rate can be considerably reduced in the future by more careful selection of patients and more extensive interruption of thoracic and upper lumbar sensory rootlets. These can be sacrificed with little handicap. Whenever possible at least one posterior root rostral and caudal to the known dermatomal innervation should be cut. Furthermore, if pain recurs the source of overlap can be determined by selective nerve blocking and an additional root or two cut at a later stage. It is well worth remembering that these operations have produced no major complications except for the single death in a poor risk patient with advanced cancer and coronary disease. This is why we have preferred to recommend posterior rhizotomy 
before recourse to cordotomy, which is no more effective in its late results and carries a definite risk of serious complications.

\section{Anterolateral Cordotomy}

When the anterolateral quadrant of the cord is transected at the second thoracic segment to a depth of 5 to $6 \mathrm{~mm}$. from the attachment of the dentate ligament to a point $2 \mathrm{~mm}$. ventral to the line of emergence of the motor roots and the level of analgesia is tested on the operating table, loss of pain and temperature sensation has usually extended up to a point between the xyphoid and umbilicus or, when the cut is made at $\mathrm{C} 2$, to the shoulder level in $95 \%$ of our patients. These essential levels for relief unfortunately are not always maintained. In our hands (White and Sweet, 1955) cordotomy at an appropriate level has given effective initial relief in the area for which the operation was undertaken in $72 \%$ of 131 patients in the late stage of malignant disease. If one excludes tumours in the upper part of the body (neck, arm, breast, and lung), in which prolonged analgesia is more difficult to

Table 6. Results of anterolateral cordotomy in malignant disease

\begin{tabular}{|c|c|c|c|c|c|c|c|c|c|}
\hline & \multirow{2}{*}{$\begin{array}{l}\text { Total } \\
\text { Cases }\end{array}$} & \multirow{2}{*}{ Level } & \multirow{2}{*}{$\begin{array}{l}\text { Uni- } \\
\text { lateral }\end{array}$} & \multirow{2}{*}{$\underset{\text { lateral }}{\mathrm{Bi-}}$} & \multirow{2}{*}{ Deaths } & \multirow{2}{*}{$\begin{array}{l}\text { Suc- } \\
\text { cess }\end{array}$} & \multicolumn{2}{|c|}{ Failures } & \multirow{2}{*}{$\begin{array}{c}\text { Success } \\
\%\end{array}$} \\
\hline & & & & & & & Early & Late & \\
\hline $\begin{array}{l}\text { Lower neck } \\
\text { and arm }\end{array}$ & 3 & $\begin{array}{l}\text { C2+ipsilat. } \\
\text { upper cervical } \\
\text { rhizotomy in } 2\end{array}$ & 3 & & 2 & 1 & & & $33 \%$ \\
\hline Breast & 10 & $\begin{array}{l}\text { Medulla } \\
\text { C2 } \\
\text { T2 }\end{array}$ & $\begin{array}{l}1 \\
3 \\
6\end{array}$ & & & $\begin{array}{l}2 \\
3\end{array}$ & $\begin{array}{l}1 \\
1 \\
3\end{array}$ & & $50 \%$ \\
\hline Lung & 9 & C3+ lower cerv. & 2 & & & 1 & & 1 & $44 \%$ \\
\hline & & $\begin{array}{l}\text { C3 } \\
\text { C2 and T2 } \\
\text { T2 }\end{array}$ & $\begin{array}{l}5 \\
1\end{array}$ & 1 & $\begin{array}{l}2 \\
1\end{array}$ & $\begin{array}{l}2 \\
1\end{array}$ & & 1 & \\
\hline G-I tract & 29 & $\begin{array}{l}\text { Medulla } \\
\text { T2 }\end{array}$ & $\frac{2}{5}$ & 22 & $\begin{array}{l}2 \\
1\end{array}$ & 23 & & 3 & $79 \%$ \\
\hline Urinary tract & 9 & $\mathrm{~T} 2$ & 4 & 5 & 1 & 6 & & 2 & $67 \%$ \\
\hline $\begin{array}{l}\text { Male genital } \\
\text { tract }\end{array}$ & 9 & $\mathbf{T} 2$ & 2 & 7 & & 8 & & 1 & $88 \%$ \\
\hline $\begin{array}{c}\text { Female genital } \\
\text { tract }\end{array}$ & 37 & $\begin{array}{l}\mathrm{C} 2 \\
\mathrm{~T} 2\end{array}$ & $\begin{array}{r}1 \\
18\end{array}$ & 18 & 3 & $\begin{array}{l}1 \\
26\end{array}$ & 4 & 3 & $73 \%$ \\
\hline Bone & 16 & $\begin{array}{l}\text { Medulla } \\
\text { T2 }\end{array}$ & $\begin{array}{l}1 \\
8\end{array}$ & 7 & $\frac{1}{2}$ & 13 & & & $81 \%$ \\
\hline $\begin{array}{l}\text { Skin, muscle, } \\
\text { fascia }\end{array}$ & 9 & $\begin{array}{l}\mathrm{C} 2 \\
\mathrm{~T} 2\end{array}$ & $\begin{array}{l}2 \\
4 \\
\end{array}$ & 3 & & $\begin{array}{l}1 \\
6 \\
\end{array}$ & $\begin{array}{l}1 \\
1\end{array}$ & & $78 \%$ \\
\hline Total & 131 & & 68 & 63 & 15 & 94 & 11 & 11 & $72 \%$ \\
\hline
\end{tabular}


obtain, $77 \%$ were freed of pain in the area for which the operation was undertaken. The best results were in carcinoma of the prostate, with a successful outcome in $88 \%$ (Table 6). Of the entire series 23 did not receive worth-while benefit and 15 died in the hospital too soon to evaluate the effect of operation. Three of these deaths were due to complications of malignant disease (ureteral obstruction, haemorrhage), but the others must be attributed to operation on poor-risk patients.

The period of survival in this group with malignant disease was brief-usually under six months, but extending up to three and a half years at the most. Late loss of analgesia is therefore not as serious a problem as it is in individuals with pain of non-malignant origin. Malignant disease, however, not infrequently leads to subsequent spread of pain into new areas, as seen in Table 7 . In 9, although the initial complaints were relieved, new pain developed subsequently at a higher level and in 21 others it was soon felt on the opposite side. Four of these patients were relieved by a second cordotomy. In the 61 individuals who survived the longest (two months to three years) there was late loss of analgesia with return

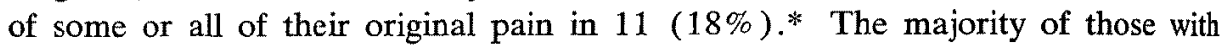
recurrences, however, were grateful for their partial relief and many did not have sufficiently severe residual symptoms to warrant further surgery, or else it did not build up to such an intensity before the terminal weeks of life, when narcotic medication became a satisfactory solution.

Table 7. Development of pain in other areas after cordotomy

\begin{tabular}{|c|c|c|c|c|}
\hline & $\begin{array}{c}\text { Higher } \\
\text { Metastases }\end{array}$ & $\begin{array}{l}\text { Involvement } \\
\text { Opposite Side }\end{array}$ & $\begin{array}{l}\text { Second } \\
\text { Cordotomy }\end{array}$ & Successful \\
\hline 3 Cervical tumours & 0 & 0 & 0 & \\
\hline 10 Breast tumours & 1 & 3 & 0 & \\
\hline 9 Lung tumours & 1 & 2 & 0 & \\
\hline 29 Gastrointestinal tumours & 2 & 4 & 2 & 2 \\
\hline 9 Urinary tract tumours & 0 & 1 & 0 & \\
\hline 9 Male genital tract tumours & 1 & 1 & 1 & 1 \\
\hline 37 Female $" \prime \prime$ & 4 & 7 & 1 & 1 \\
\hline 16 Bone tumours & 0 & 3 & 0 & \\
\hline 9 Soft tissue tumours & 0 & 0 & 0 & \\
\hline 131 cases & 9 & 21 & 4 & 4 \\
\hline
\end{tabular}

In the neuralgias of traumatic origin and other non-malignant conditions, which are reviewed in Table 8, results were impressive at first with $95 \%$ freed of their complaints when they left the hospital. As previously pointed out, at a time between three and six months, when most of the patients with malignant disease die, analgesia becomes incomplete in $30 \%$ (Fig. 5). Beyond this period

\footnotetext{
* These late recurrences are included amongst the failures listed in Table 6.
} 
Table 8. Results of anterolateral cordotomy in non-malignant disease

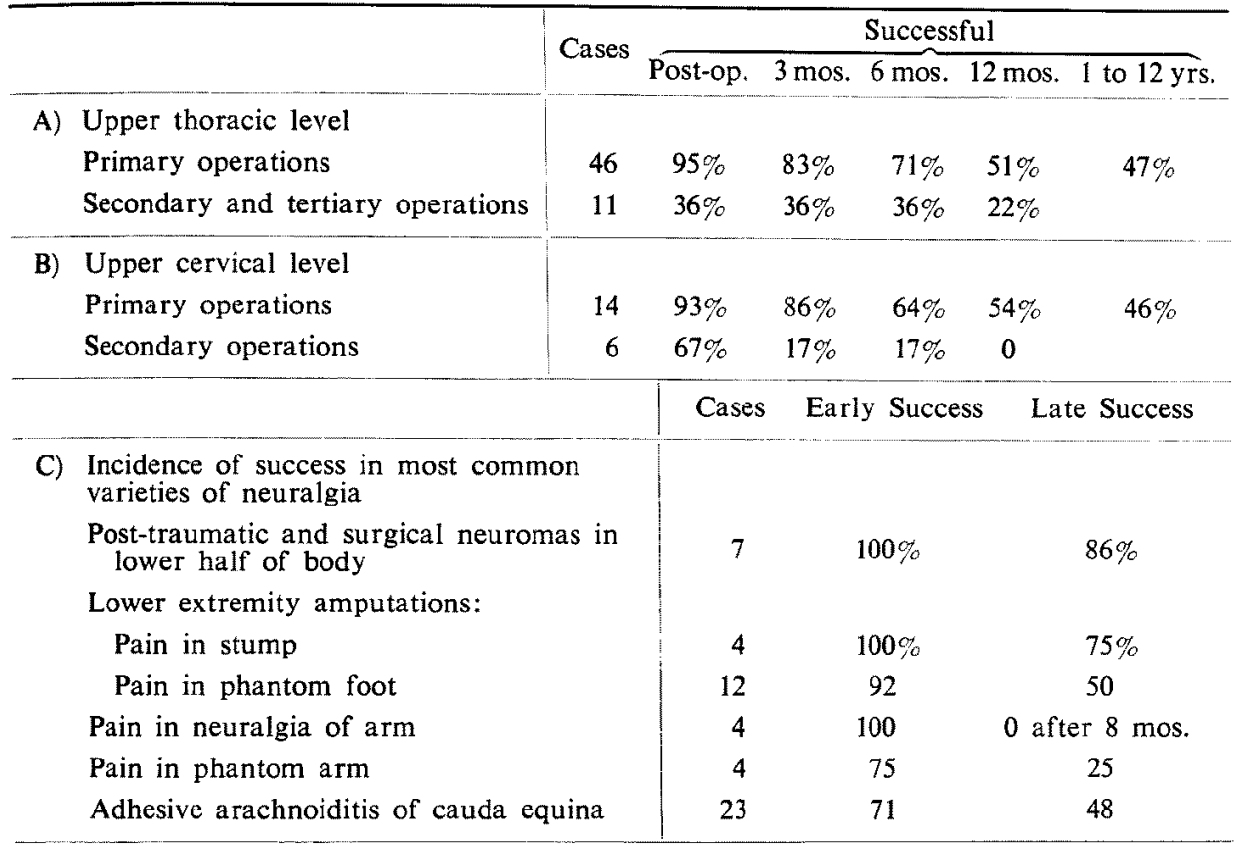

Progressive Recovery of Sensibility after Bilateral Cordotomy

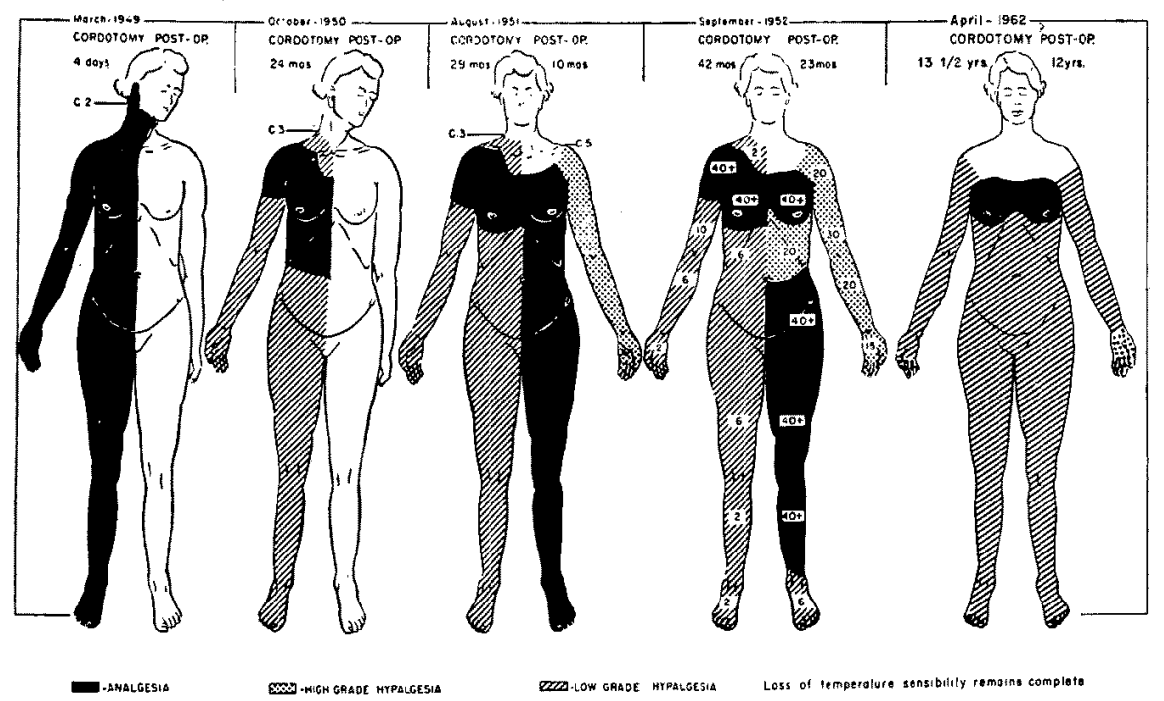

Figure 5. Replacement of analgesia by hypalgesia in a patient followed $13 \frac{1}{2}$ years after upper cervical cordotomy. The numerals indicate sensibility to pin-prick in grams. Reproduced with additions from article by the author in Archives of Neurology and Psychiatry, 71: 1-23, 1954, with permission of the American Medical Association, Chicago. 
there is a progressive decline in the effectiveness of the operation to the point where slightly under a half of the patients have had some ability to detect the difference between the prick of a pin and contact with a blunt object accompanied by a return of pain after a year or more has passed. The progressive replacement of analgesia by hypalgesia is illustrated in Figure 6.

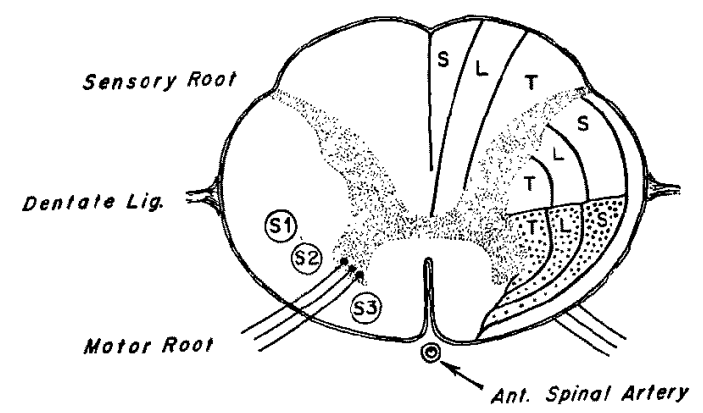

Figure 6. Anatomical diagram of spinal cord and sites of stimulation. On right, normal topographical arrangement of axons is shown in posterior columns, corticospinal and spinothalamic tracts.

$\mathrm{T}=$ thoracic, $\mathbf{L}=$ lumbar, $\mathrm{S}=$ sacral axons.

In patient referred to in text electrical stimulation on left side evoked no painful response at $\mathbf{S} 1$ and $\mathbf{S} 2$. Stimulation at $\mathbf{S} 3$ caused pain felt in contralateral leg.

The results are somewhat variable in different conditions (Table 8C) with $86 \%$ of patients suffering from traumatic injuries of peripheral nerves in the lower extremity maintaining their initial satisfactory results as compared with only $49 \%$ of those with adhesive arachnoiditis. In this condition constriction of the pial blood supply may result in an ascending myelitis. This is shown by the appearance of mass reflexes with spontaneous contractures of the leg muscles. Even when a good level of analgesia is maintained this cramp-like pain of tense muscles is not relieved. With pain localized in an amputation stump above or below the knee lasting success has been achieved in $75 \%$, whereas in the intensely painful lower extremity phantoms relief has been maintained in only $50 \%$. While postural sensations remain after a successful anterolateral cordotomy, the painful element nearly always disappears as long as analgesia remains complete. Unfortunately in the upper extremity analgesia to the chin failed to produce symptomatic relief in 1 case and faded in 2 others with return of the original pain. The only patient in whom the painful element of the phantom has been eliminated for twelve years, following a medullary section of the spinothalamic tract by Dr. Sweet, complains of disagreeable paraesthesias, which have become increasingly troublesome in recent years. Four other patients, in whom I have carried out high cervical cordotomies for neuralgia following trauma to the hand, have experienced return of pain within six weeks to eight months as analgesia was replaced by hypalgesia. Falconer (1953), however, has reported 5 of 6 victims of painful phantoms after upper extremity 
amputations who have remained free of pain from two to seven years with only a single recurrence.

In addition to these disheartening experiences, we have had poor success in attempting to restore full analgesia once it has been replaced by hypalgesia. After 9 secondary and 2 tertiary upper thoracic cordotomies, only 2 of the 9 who have been followed up to a year have remained successful. Relatively early return of hypalgesia has been invariable when pain is present in the upper extremity and spinothalamic tractomy in the medulla has proved no more effective. At a high thoracic level Sweet and I have had ultimate success in 2 tertiary operations by awakening the patient and stimulating the secondary pain-conducting fibres. In 1 we found an abnormal position of these axons, well in front of the line of ventral roots. This is illustrated diagrammatically in Figure 7 in relation to Walker's (1940) concept of the topographic arrangement of the pain fibres in the anterolateral column. In the other we were able to demonstrate ipsilateral conduction by stimulation and it was necessary to carry out a bilateral tractotomy to eliminate pain in the right leg. Analgesia is still present six years afterwards.

Complications after cordotomy are shown in Table 9. These compare favourably with those reported by others, especially the recent series published by McKissock (1961). Whether the anterolateral column is transected in the upper cervical or thoracic level appears to make little difference. In the series with malignant disease difficulties with voiding and weakness of the leg on the side of

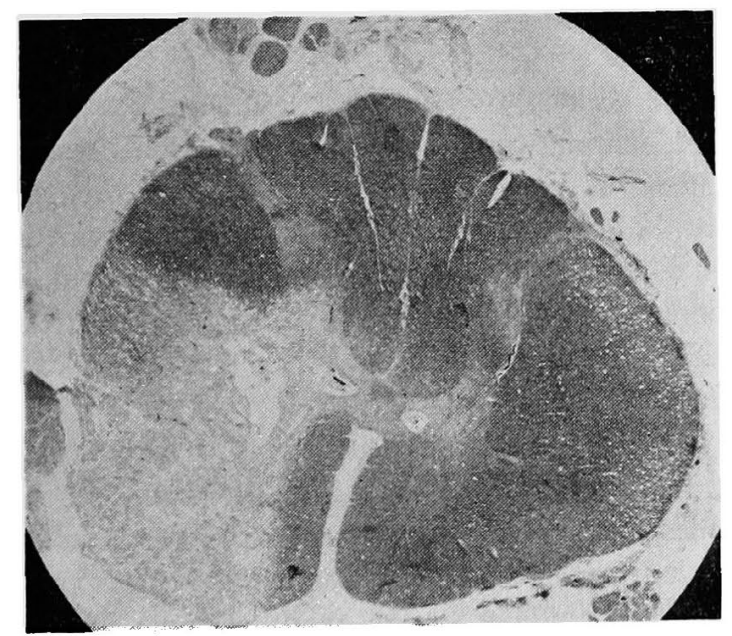

Figure 7. Postmortem extent of anterolateral transection at T2 that resulted in analgesia to T3. Although there is partial degeneration of axons in anterior half of corticospinal tract, there was no weakness of the leg or change in the reflexes.

From article by the author in Archives of Neurology ana Psychiatry, 71: 1-23, 1954, with permission of the American Medical Association, Chicago. 
Table 9. Complications in malignant disease

\begin{tabular}{|c|c|c|c|c|c|c|c|}
\hline & & $\begin{array}{l}\text { No. of } \\
\text { Cases }\end{array}$ & Deaths & $\begin{array}{l}\text { Blad- } \\
\text { der* }\end{array}$ & $\begin{array}{l}\text { Motor } \\
\text { Para- } \\
\text { lysis* }\end{array}$ & $\begin{array}{l}\text { Hypo- } \\
\text { tension }\end{array}$ & $\begin{array}{l}\text { Dysaes- } \\
\text { thesia }\end{array}$ \\
\hline Lower neck and arm: & Unilateral & 3 & 2 & & & & \\
\hline Breast: & $\begin{array}{l}\text { Unilateral } \\
\text { Bilateral }\end{array}$ & $\begin{array}{l}8 \\
2\end{array}$ & 1 & & 1 & & \\
\hline Lung: & $\begin{array}{l}\text { Unilateral } \\
\text { Bilateral }\end{array}$ & $\begin{array}{l}8 \\
1\end{array}$ & $\begin{array}{l}2 \\
1\end{array}$ & 1 & 1 & & \\
\hline Gastrointestinal Tract: & $\begin{array}{l}\text { Unilateral } \\
\text { Bilateral }\end{array}$ & $\begin{array}{l}10 \\
19\end{array}$ & $\begin{array}{l}2 \\
1\end{array}$ & 8 & $\frac{1}{3}$ & & 1 \\
\hline Kidney: & Unilateral & 2 & & 1 & & & \\
\hline Bladder: & Bilateral & 7 & 1 & & & & \\
\hline Prostate, etc.: & $\begin{array}{l}\text { Unilateral } \\
\text { Bilateral }\end{array}$ & $\begin{array}{l}2 \\
7\end{array}$ & & 2 & 1 & & \\
\hline Uterus, etc.: & $\begin{array}{l}\text { Unilateral } \\
\text { Bilateral }\end{array}$ & $\begin{array}{l}18 \\
19\end{array}$ & 2 & $\begin{array}{l}3 \\
5\end{array}$ & $\begin{array}{l}1 \\
3\end{array}$ & 2 & 3 \\
\hline Bone: & $\begin{array}{l}\text { Unilateral } \\
\text { Bilateral }\end{array}$ & $\begin{array}{l}9 \\
7\end{array}$ & $\begin{array}{l}1 \\
2\end{array}$ & 2 & 2 & 1 & \\
\hline Skin: & Unilateral & 6 & & & & & \\
\hline \multirow[t]{2}{*}{ Soft Parts: } & Bilateral & 3 & & 1 & 1 & & \\
\hline & $\begin{array}{l}\text { Unilateral } \\
\text { Bilateral }\end{array}$ & $\begin{array}{l}66 \\
65\end{array}$ & $\begin{array}{l}7 \\
8\end{array}$ & $\begin{array}{r}5 \\
18\end{array}$ & $\begin{array}{r}4 \\
10\end{array}$ & $\begin{array}{l}0 \\
3\end{array}$ & $\begin{array}{l}0 \\
4\end{array}$ \\
\hline
\end{tabular}

* Brief paralyses of bladder or ipsilateral extremity which soon cleared are not included in this table.

the incision were not a serious problem after unilateral cordotomy, but became of greater concern after bilateral operation. When the tracts were cut on both sides leg weakness, at times severe, developed in $15 \%$ even though precautions were taken never to place the incisions within the same spinal segment. Difficulties with urination developed after all the bilateral operations and required permanent use of an in-lying catheter in $29 \%$ if the incisions were made at one stage, but need for prolonged catheterization was reduced to $16 \%$ if the cordotomy was carried out in separate stages.

While there were 15 deaths amongst the 131 patients operated upon for malignant disease, there were none in those with benign neuralgias. After 69 unilateral cordotomies in the latter series damage to the bladder has been serious in 2. One of these individuals had pre-existent impairment of vesical function as a result of adhesive arachnoidities of the cauda equina. This was not made any worse by operation, but continued to progress for seven years. The other had the misfortune of developing a resistant cystitis after brief postoperative catheterization. This became chronic and over a period of five years resulted in a thick-walled, irritable bladder. Diversion of the urinary stream to an ileal loop bladder was ultimately necessary in each. In the non-malignant group leg weakness has not been a serious problem and never occurred in any of my 16 amputees, where weak-

$$
-16-
$$


ness of the good leg would be a serious handicap.

The most serious late complication in the replacement of analgesia by disagreeable paraesthesia or dysaesthesia. This has not been severe and has only been a source of mild complaint in 4 of the 131 individuals who had cordotomy performed for malignant pain, as it rarely appears before analgesia fades. Attention was first called to this complication by Sjöqvist (1949) and by Lapresle and Guiot (1953). In its most severe form, which has developed in 2 of my 70 cordotomized patients with prolonged survival, the burning pain on even light contact with clothing has been as intense as in the thalamic syndrome of Déjerine-Roussy. It has persisted in these 2 women for seven years. Milder examples which have not been incapacitating have occurred in 11 other individuals. In 1, a patient with a lower extremity phantom whose pain recurred four years after cordotomy, the paraesthesia has disappeared and he remains free of discomfort seven years after a successful secondary tractomy.

The cause of late replacement of analgesia by hypalgesia is not known. In a previous article we (White, Richardson, and Sweet, 1956) have described postmortem examination of our cordotomy incisions in 18 individuals who died of malignant disease. Microscopic examination at the level of transection showed that virtually the entire anterior quadrant had often been cut across (Fig. 8). Recovery of a few contused but viable peripheral fibres could account for early but not late return of pain. This must therefore be transmitted by sensory fibres in other portions of the cord (juxtagriseal or posterior column axons) as hypothecated by Foerster and Gagel (1932) and discussed at length in a recent article by Osácar et al. (1961). If accessory routes of pain conduction were the explanation one would expect them to open up before a year has passed. Therefore the possibility must be borne in mind that is an occasional instance where analgesia fades after a prolonged period has elapsed a few severed secondary pain-conducting axons may regenerate, bridge the thin cordotomy cicatrix and again find their way to the thalamus or reticular formation in the mid-brain. After years of trial I have finally obtained the spinal cord of a woman who committed suicide after unilateral cordotomy for intercostal neuralgia. For two and a half years she maintained full analgesia, only to have it fade with a return of pain. Prolonged suffering coupled with drug adiction led to termination of her life. Microscopic sections at the level of cordotomy are being cut serially, so that the question of regeneration may be settled within a few months. 


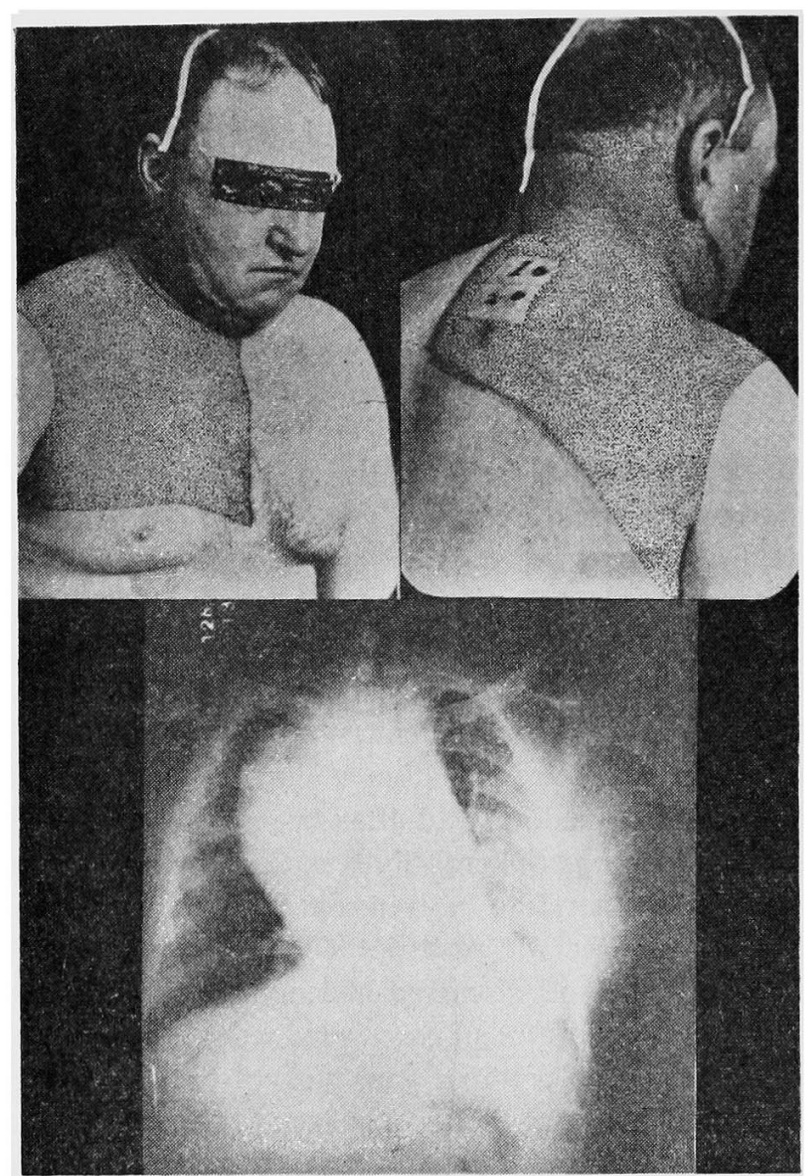

Figure 8. Aneurysm of ascending arch of aorta and area of referred pain.

The dots indicate sites of insertion of needles for paravertebral injection of alcohol into first and second thoracic sympathetic ganglia. This resulted in relief of pain over the last 3 months of life.

From article by the author in Journal of the American Medical Association, 99: 10-13, 1932, with permission of the A. M. A., Chicago.

\section{SYMPATHECTOMY}

According to Cannon (1932) and the earlier pioneer physiologists the sympathetic nervous system is concerned with homeostatic control of smooth muscle and glandular activity. Knowledge of its very important role in transmission of pain in visceral disease and as a factor in producing pain in causalgia and other related sympathetic dystrophies has developed slowly over the past forty-five years. Pain- 
conducting fibres identical with those found in cranial and spinal sensory nerves run to nearly all the viscera in the paravertebral ganglionated chains, their rami communicantes, and the cardiac and splanchnic nerves. There is, however, no sound evidence that they are distributed to the brachial and lumbosacral plexuses as an accessory afferent system. Dr. Sweet and I (1955) have stimulated both stellate and lumbar ganglia on numerous occasions in conscious, co-operative patients. This has evoked pain in the chest, abdomen, or pelvis; never in the limbs, unless the individual tested had causalgia. Yet regional sympathetic denervation can put an end to pain in causalgia and certain other peripheral neuralgias following trauma. This procedure is most likely to succeed in individuals with abnormally cool, sweaty extremities, especially when the pain is made worse by exposure to cold or emotional stimuli. In these cases relief must be related to abolition of the sympathetic efferent discharge, as first postulated by Doupe, Cullen, and Chance (1944).

As the results $I$ shall report will show, sympathectomy in properly selected cases produces a high rate of permanent cure. Its potential effectiveness can be readily tested by infiltration of local anaesthetic agents to block temporarily the stellate or lumbar ganglia, the cardiac or splanchnic nerves. Unlike posterior root section, there is no problem of nerve overlap, and pain does not have such a way of recurring months or years later as it does all too often after anterolateral cordotomy. In addition, complications are rare and pain can be eliminated without producing sensory loss or annoying paraesthesias. The literature on the development of sympathetic surgery for the relief of pain by Leriche and others, together with its bibliography and descriptions of diagnostic blocking and surgical procedures, is given in my two monographs (White, Smithwick, and Simeone, 1952; White and Sweet, 1955).

1. Sympathectomy in Peripheral Neuralgia: Results of sympathetic denervation in peripheral neuralgias in 27 cases after clear-cut relief by preliminary diagnostic stellate or lumbar block are summarized in Table 10. In some of these cases one or more blocks with a local anaesthetic were followed by permanent relief, but in the majority it was necessary to resect the second and third thoracic or lumber ganglia. The stellate can usually be left intact, sparing the patient the needless ptosis and miosis of a Horner's sign.

In order to emphasize the effectiveness of sympathetic surgery in the three common varieties of peripheral neuralgia for which we have found this operation so useful I shall give brief case histories of a typical example of each.

\section{Diffuse Neuralgia Following Digital Amputation}

A characteristic example of this was a 30-year-old male who crushed the terminal phalanx of his index finger in a box-making machine. The tip of the finger had been amputated and the stump revised when pain, radiating diffusely up the arm to his axilla, became unbearable (Fig. 9). When he was referred to me in 1929 I was impressed by his cold, moist, cyanotic extremities. Because his pain 
Table 10. Results of sympathectomy in peripheral neuralgia

\begin{tabular}{|c|c|c|c|c|}
\hline Condition & $\begin{array}{l}\text { Total } \\
\text { Cases }\end{array}$ & Relief & Failure & Follow-up \\
\hline $\begin{array}{l}\text { Digital injuries and amputations: } \\
\text { Extremities cold and moist. Pain increased } \\
\text { on exposure to cold and relieved by sym- } \\
\text { pathetic block. }\end{array}$ & 7 & 6 & 1 & 2 mos. to $20 \mathrm{yrs}$ \\
\hline $\begin{array}{l}\text { Post-traumatic arthritis:* } \\
\text { Pain also increased by over-active vaso- } \\
\text { motor reflexes. }\end{array}$ & 7 & 7 & 0 & $2 \mathrm{mos}$. to $12 \mathrm{mos}$. \\
\hline $\begin{array}{l}\text { Causalgia: } \\
\text { Pain increased on emotional or thermal } \\
\text { stimuli. }\end{array}$ & 13 & 13 & 0 & $2 \mathrm{mos}$, to $15 \mathrm{yrs}$ \\
\hline \multicolumn{5}{|c|}{$\begin{array}{l}\text { Half of the patients with post-traumatic arthritis were relieved by single or repeated } \\
\text { injections of the regional sympathetic ganglia, the other half by upper thoracic or } \\
\text { lumbar sympathectomy. } \\
\text { In the majority of the upper thoracic sympathectomies the chain was cut below } \\
\text { its third ganglion and all central connections with the second and third intercostal } \\
\text { nerves severed. Leaving the stellate ganglion intact (but disconnected from the pre- } \\
\text { ganglionic vaso- and sudo-motor axons to the arm) spares the patient the unnecessary } \\
\text { complication of a Horner's syndrome. }\end{array}$} \\
\hline
\end{tabular}

became much worse on exposure to cold a stellate block was tried. As his fingers became warm and dry his pain disappeared for several hours. Upper thoracic ganglionectomy has relieved his discomfort for twenty years. He has recently been admitted for a coronary occlusion, which was painful only on the right side of his chest and arm, in which the sympathetic innervation remained intact.

\section{Post-traumatic Arthritis (Sympathetic Dystrophy)}

A 70-year-old hotel keeper dislocated his shoulder in a fall downstairs in 1949. Although this was promptly reduced he developed pain throughout his right arm. This prevented movement and led to severe atrophy of disuse. On entry to the Massachusetts General Hospital twelve months later he carried his hand wrapped up in a blanket and supported on a pillow. On removal of these the picture seen in Figure 10 was disclosed-extreme atrophy and fibrosis with clawing of the fingers and long finger-naiis, too painful to cut. Any movement of his fingers or wrist was extremely painful, as were rubbing and touching the skin. All the bones in the arm were osteoporotic. In this case there was no unusual sweating or sensitivity to cold, but nevertheless his pain and dysaesthesia disappeared after a single stellate block and never recurred during the ensuing year. It was unfortunate in this case that treatment could not have been started earlier before fibrotic changes had become irreversible.

\section{Causalgia}

Although this syndrome of Weir Mitchell (1872) is rarely seen in peacetime, 


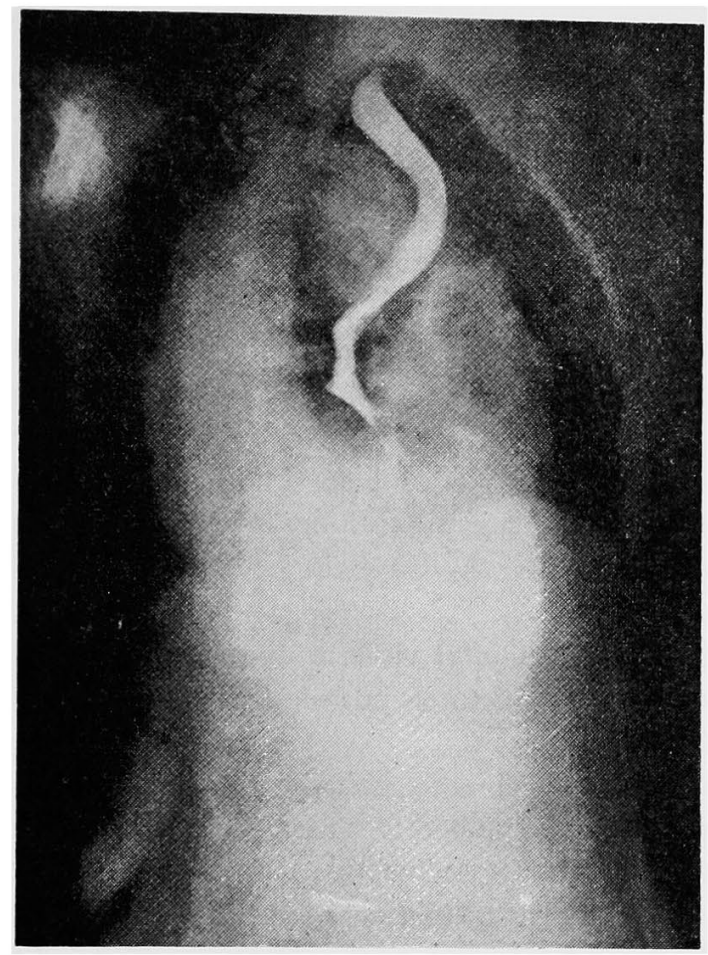

Figure 9. Painful aneurysms of the ascending arch and mid-thoracic portions of the aorta are outlined by barium in the oesophagus. This woman's pain was relieved by cutting the posterior roots of the upper seven thoracic spinal nerves.

From Pain, by White and Sweet, 1955, with permission of Charles C. Thomas, Publisher, Springfield, IIl.

I have had the good fortune to treat 14 cases while serving in the U. S. Navy Medical Corps in World War II. These individuals all had penetrating wounds with partial injuries of major nerve trunks in their extremities. All suffered immediate onset of burning pain. This became agonizingly severe on exposure to cold, tropical heat, or emotional stimuli. Pain could be relieved for a few hours by stellate or lumbar block with a local anaesthetic and disappeared permanently after regional sympathetic denervation. In 1948 I was able to review 66 cases of causalgia that had been treated by sympathectomy in World War II and found that none had had recurrence of their burning pain.

A typical example is the case history of a 28 -year-old private in the Marine Corps who had a rifle bullet pass between the bones in his mid-forearm in 1945 (Fig. 11), producing a lateral neuroma of the medical nerve. In this patient the area of burning pain, trophic changes in the skin, and tapering fingers were limited to the territory of the median nerve. For this reason a neurolysis of this nerve 
was performed, with excision of the lateral neuroma, but without any relief. Diagnostic procaine block and subsequent thoracic sympathectomy then gave a most satisfactory result. After this experience I learned to carry out sympathetic surgery as the primary procedure.

2. Sympathectomy in Visceral Neuralgia: Resection or chemical destruction of regional sympathetic ganglia, the splanchnic or renal plexuses is a very effective method of relieving otherwise intractable pain in disease of the coronary arteries, aorta, upper abdominal viscera, and kidneys. Section of the posterior spinal roots, if the level of afferent inflow is not too extensive, is equally effective. The source of pain must be entirely visceral. Sympathectomy is likely to fail in cases of carcinoma because pain is rarely a problem until the malignant cells invade the thoracic or abdominal walls. Sympathectomy also is ineffective in pain from the blader, prostate, or cervix uteri, as the pain pathways from these structures run in the sacral nerves.

Results in 121 cases of painful visceral disease are summarized in Table 11 and by a number of brief case histories added to illustrate the value of interrupting the sympathetic trunks.

In the case of severe angina decubitus which does not respond to nitrites relief by neurosurgery is less frequently called for to-day than before the advent of reduction of thyroid activity by radioactive iodine. The pathways of cardiac pain through the upper four thoracic sympathetic ganglia and the corresponding thoracic spinal roots have been established since the discovery of the direct cardiac nerves (summarized by Mitchell, 1953) and the experimental work of White, Garrey, and Atkins (1933) on dogs. Occasionally our cardiologists still prefer this form of treatment.

A striking recent example is a 42-year-old head-nurse at a local hospital who had had a severe coronary thrombosis. She was referred by our cardiologists because of angina decubitus which prevented sleep and made relaxation impossible. She had shown little response to nitroglycerine and required narcotics to an extent that threatened addiction. This was an intelligent, high-strung woman with mild hypertension, but otherwise in good health except for her coronary disease. Her anginal attacks were unusually severe, spreading from the precordial area down the left arm and coming with such intensity that she would hyperventilate and develop carpopedal spasm. In the hope that she could be relieved of her pain and might then, with rest and relaxation, pick up a better coronary irrigation and be able to return to work as a nurse, sympathectomy was recommended in preference to inducing a state of thyroid deficiency by radioactive iodine. As this patient so often had attacks with any form of excitement and was a poor operative risk, general anaesthesia was induced in her room. Pentothalfluothane was administered with intratracheal intubation. The heart was monitored by electrocardiography. In the right lateral position and by the posterior approach, the upper four thoracic ganglia were resected on the left side on $12 / 29 / 61$. Recovery was uneventful and 


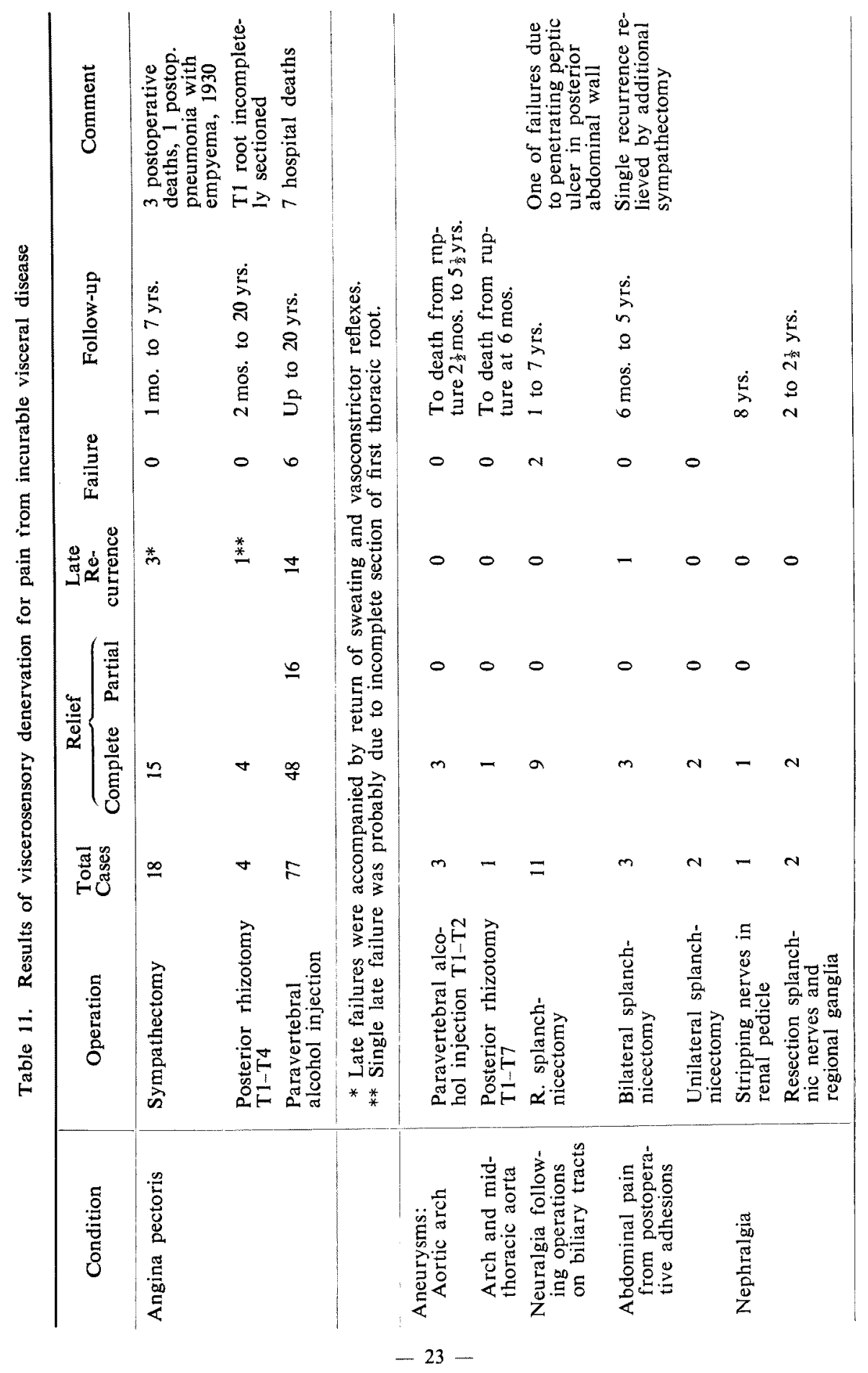


she left the hospital pain free. She has had no further attacks of angina since and was able to resume her work as a nurse within three months.

Prior to modern intratracheal anaesthesia 77 patients were treated by chemical destruction of the upper thoracic ganglia by paravertebral injection of alcohol. Relief of cardiac pain could be counted on provided the patient developed a Horner's sign and a warm, dry hand. A number of these individuals who had severe angina decubitus in the 1930's have remained free of attacks and able to return to moderate activity for periods up to twenty years. In the more recent series with surgical removal of the ganglia relief of pain has been consistent. This has also been true of posterior root section when the upper four thoracic roots have all been interrupted. One such patient, who has been operated on both by me and Dr. Bronson Ray in New York, has continued to carry on an extensive practice of medicine over the past twenty years. He has warning signals on over-exertion, which consist of a sense of painless constriction in his throat and precordium. When he has these he takes nitroglycerine and reduces his activity, but beyond taking a siesta each day after lunch he has been able to carry on a heavy schedule as chief of the medical service in a large hospital. In this and other similar cases it seems probable that these individuals, given release from pain and a chance to sleep and relax free from fear of repeated attacks, must have developed an effective collateral coronary circulation. On the debit side, the mortality rate has been fairly high and there have been a few late recurrences of angina with detectable return of sweating in the hand after alcohol injection and even after resection of the ganglia.

Injection of the upper thoracic sympathetic ganglia with alcohol or interrupting the cardio-aortic sensory fibers by posterior root section has also given relief of pain from aneurysms of the aortic arch. Figure 12 shows an aneurysm of the ascending aortic arch which produced brassy cough and intense pain over the right shoulder, neck, and occipital region. In 1929 this was the first attempt to relieve aneurysmal pain and it was possible to demonstrate its route of conduction by paravertebral block with procaine. Pain was relieved by a second injection with alcohol of the first and second thoracic ganglia for a three months' period before fatal rupture. In a situation of this sort, where an aneurysm lies in contact with the vertebral bodies, surgical removal of the ganglia might well lead to fatal rupture of the adherent sac. Therefore it is necessary either to destroy the ganglia by paravertebral injection or to cut the sensory fibres in the posterior spinal roots.

In Figure 13 barium in the oesophagus outlines two aneurysms in the descending arch and mid-thoracic portions of the aorta. This syphilitic woman had bouts of uncontrollable cough with agonizing pain in her left chest. Here, after a preliminary test block with xylocaine, I cut the upper seven thoracic posterior roots in two stages. This took away all her pain over the next seven months until she died from sudden haemorrhage.

Chronic colicky pain produced by distension of biliary ducts following disease 
of the gall bladder and multiple operations, back pressure on the renal pedicle, and intermittent partial obstruction of the small bowel in patients with post-operative adhesions have all responded well to splanchnicectomy. Nineteen cases are summarized in Table 11 and a brief description of each type is given below.

In the series of 12 patients with persistent pain after multiple operations on the gall bladder and biliary ducts, all but 2 have remained free of pain after a rightsided splanchnicectomy. The following is a typical case history:

A 45-year-old woman entered the Massachusetts General Hospital in 1935 after a prolonged history of gall bladder disease. Five years previously her gall bladder had been drained, then finally removed. A year later she developed increasingly severe right upper quadrant pain with a tender liver and subclinical jaundice. A plastic procedure was performed on the stenosed ampulla and the patient sent home with an inlying $\mathbf{T}$ tube in the common bile duct. As long as the catheter drained she remained free of pain, but her characteristic discomfort recurred as soon as the tube was clamped. It returned with its former severity a few weeks later when the tube came out and the sinus closed. She complained of constant right upper quadrant discomfort and sharp attacks of pain radiating to her scapular region and right arm. As she had no jaundice it was concluded that bile must be entering the duodenum, but under back pressure from the stenosed ampulla of Vater. With the evidence of the effective relief of biliary pain by splanchnic block derived from previous cases, it seemed wise to submit her to a simple sympathetic denervation for relief of pain rather than a very difficult reexploration of the common bile duct. On 5/2/38 Dr. Smithwick therefore resected the right major and minor splanchnic nerves with a short length of paravertebral chain through Peet's eleventh rib supradiaphragmatic approach. The patient left the hospital ten days later and has remained free of pain.

Similar favourable results in the treatment of persistent pain from the biliary tract after failure of conventional surgical procedures have been reported by Womack and Crider (1947) and by Mallet-Guy and Feroldi (1950).

Troublesome colicky pain due to adhesions and gas traps in kinked loops of small intestine may follow multiple laparotomies. Unless obstruction is severe, relief of pain from adhesions with intestinal distension and disordered peristaltic activity may be achieved by splanchnicectomy. Five patients with this syndrome have been operated upon at the Massachusetts General Hospital, 4 of which have been described by Sarnoff, Arrowood, and Chapman (1948). Preliminary testing with procaine by either selective subarachnoid or paravertebral splanchnic block has made it possible to convince the patient as well as the referring surgeon of the benefits of the proposed sympathectomy. Of the 5 patients listed in Table 11, 1 had a late return of symptoms requiring additional section of the left splanchnic trunk, which had regenerated. All have remained free of symptoms for periods up to five years.

In contrast, sympathectomy has nothing to offer in the control of pain from 
the large intestine, as the visceral afferent pathway from the lower gut is over the sacral nerves. Also in cases of carcinoma sympathectomy is contraindicated, as in this situation the pain is caused by infiltration of somatic nerves in the retroperitoneal area and lumbosacral plexuses.

In the final group of 3 patients listed in Table 11 the urologists had been unable to discover any organic lesion. Nevertheless these individuals suffered severely from typical renal colic and their symptoms could be reproduced by distending the renal pelvis. When it had been demonstrated that their pain was relieved by paravertebral block from $\mathrm{T} 10$ to $\mathrm{L} 1$ the kidney was explored and found to have no abnormality. Although no pathological cause for the persistent pain was found, the results of renal sympathetic denervation were very successful and are known to have been maintained from two to eight years. Similar experiences have been reported by Stone (1934), by Peirson and Deming in their discussion of Stone's paper, and by Gunnar Bauer (1944) in a large series followed for five years or more.

\section{CONCLUSIONS}

These have been our experiences with persistent, disabling pain that has been intractable to medical measures or direct surgical correction. I am sorry that time does not permit a description of Maher's method of subarachnoid injection of phenol in glycerine or of our present method of conservative frontal leucotomy in stages by means of inlying electrodes and radio-frequency coagulation. Phenol subarachnoid block is making it possible to eliminate the need for cordotomy in over half the cases of pain involving the lumbosacral plexus and lower intercostal nerves (Mark et al., 1962). By means of coagulation with radio-frequency current of the frontal white matter in conservative stages it is possible to relieve pain, the need for narcotis, and fear of terminal cancer in many individuals without producing serious psychological deterioration (White, 1962). As these methods have been developed in the last few years it is not yet possible to evaluate their long-term results and they are therefore not included in this paper.

\section{REFERENCES}

1) Bauer, G.: Late results of denervation of the kidney for renal pain. Acta Chir. Scand. 1944, 90: 460-468.

2) Brodal, A.: The cranial nerves: Anatomy and anatomico-clinical correlations. Springfield, Illinois, Charles C. Thomas, 1959, 141 pp.

3) Cannon, W. B.: The wiscom of the body. New York, W. W. Norton \& Co., 1932, $312 \mathrm{pp}$.

4) Craig, W. Mck.: The diagnosis and treatment of trigeminal neuralgia. South. Surg., 1941, 10: 17-29.

5) Dandy, W. E : Operative relief from pain in lesions of the mouth, tongue and throat. Arch. Surg., 1929, 19: 143-148. 
6) Doupe, J., Culien, C. H. and Chance, G. Q.: Post-traumatic pain and the causalgic syndrome. J. Neurol. Neurosurg. Psychiat., 1944, 7: 33-48.

7) Falconer, M. A.: Surgical treatment of intractable phantom-limb pain. Brit. Med. J., 1953, 1: 299-304.

8) Foerster, O.: The dermatomes in man. Brain, 1933, 56: 1-39.

9) Foerster, $O$. and Gagel, O.: Die Vorderseitenstrangdurchschneidung beim Menschen. Z. ges. Neurol. Psychiat., 1932, 138: 1-92.

10) Grant, F. C.: Results in the operative treatment of major trigeminal neuralgia. Ann. Surg., 1938, 107: 14-19.

11) Grant, F. C.: Surgical methods for relief of pain. Bull. N. Y. Acad. Med., 1943, 19: 373-385.

12) Grant, F. C.: Complications accompanying surgical relief of pain in trigeminal neuralgia. Amer. J. Surg., 1948, 75: 42-47.

13) Grant, F. C. and Weinberger, L. M.: Experiences with intramedullary tractotomy. I. Relief of facial pain and summary of operative results. Arch. Surg., 1941, 42: 681-692.

14) Grantham, E. G. and Spurling, R. G.: Selective lobotomy in the treatment of intractable pain. Ann. Surg., 1953, 137: 602-608.

15) Guidetti, B.: Tractotomy for the relief of trigeminal neuralgia. Observations in 124 cases. J. Neurosurg., 1950, 7: 499-508.

16) Hamby, W. B., Shinners, B. M. and Marsh, I. A.: Trigeminal tractotomy: Observations on forty-eight cases. Arch. Surg., 1948, 57: 171-177.

17) Kerr, F. W. L.: Facial, vagal and glossopharyngeal nerves in the cat. Arch. Neurol., 1962, 6: 264-281.

18) Kunc, Z.: La localisation des trajets de la douleur des nerfs IX, $X$ et VII dans moelle allongée et la possibilité de leur tractotomie seléctive. Acta Neurochir., 1960, 8: 327334.

19) Lapresle, J. and Guiot, G.: Etude des résultats éloignés, et en particulier des séquelles neurologiques à type de 'douleur centrale', dans 8 cas de cordotomie antéro-latérale pour coxarthrose. Sem. Hôp. Paris, 1953, 29: 2189-2198.

20) McKissock, W.: Spinothalamic cordotomy: Reassessment of effectiveness and limitations. Abstr. 2nd Internat. Congr. Neurol. Surg., 1961 (Excerpta Medica Internat. Congr. Series, No. 36), E 27.

21) Maliet-Guy, P. and Feroldi, J.: Le facteur "névrome d'amputation" dans le mécanisme de certaines récidives apres cholécystectomie. Mém. Acad. Chir., 1950, 76: 123-128.

22) Mark, V. H., White, J. C., Zervas, N. T., Ervin, F. R. and Richardson, E. P.: The use of intrathecal phenol for the relief of chronic severe pain. In press, 1962.

23) Mitchell, G. A. G.: Anatomy of the autonomic nervous system. Edinburgh and London, Livingstone, 1953, 356 pp.

24) Mitchell, S. W.: Injuries of nerves and their consequences. Philadelphia, J. B. Lippincott \& Co., 1872, 377 pp.

25) Nathan, P. W. and Sears, T. A.: Effects of posterior root section on the activity of some muscles in man. J. Neurol. Neurosurg. Psychiat., 1960, 23: 10-22.

26) Northfield, D. W. C.: Retrogasserian rhizotomy and other operations for trigeminal neuralgia: Reassessment of their effectiveness and limitations. Abstr. 2nd Internat. Congr. Neurol. Surg., 1961 (Excerpta Medica Internat. Congr. Series, No. 36), E 23.

27) Osácar, E. M., Meyer, A. E. and Jakab, I.: A histologically verified bilateral anterolateral chordotomy without cutaneous sensory loss. A case report. Acta Neurochir., 1961, 9: 525-537.

28) Peet, M. M. and Schneider, R. C.: Trigeminal neuralgia: A review of 689 cases with a follow-up study of 65 per cent of the group. J. Neurosurg., 1952, 9: 367-377. 
29) Pudenz, R. H. and Shelden, C. H.: Experiences with foraminal decompression in the surgical treatment of tic douloureux. Presented before American Academy of Neurological Surgery, New York, Oct. 1, 1952.

30) Sachs, E.: The diagnosis and treatment of trigeminal neuralgia. Tri-state Med. J., 1935, 7: $1416-1420$.

31) Sarnoff, S. J., Arrowood, J. G. and Chapman, W. P.: Differential spinal block. N. The investigation of intestinal dyskinesia, colonic atony, and visceral afferent fibers. Surg. Gynec. Obstet., 1948, 86: 571-581.

32) Scarff, J. E.: Unilateral prefrontal lobotomy for the relief of intractable pain. Report of 58 cases with special consideration of failures. J. Neurosurg., 1950, 7: 330-336.

33) Sjöqvist, O.: Ten years' experience with trigeminal tractotomy. Brasil Méd. Cirúrg., 1948, 10: 259-274.

34) Sjöqvist, O.: Surgical section of pain tracts and pathways in the spinal cord and brain stem. IVe Congrès Neurol. Internat., 1949, Abstr. 1: 119-132.

35) Stone, E.: Renal sympathectomy: Report of two cases, including one fatality. New Engl. J. Med., 1934, 210: 1257-1262.

36) Stookey, B. and Ransohoff, J.: Trigeminal neuralgia, its history and treatment. Springfield, Ill., Charles C. Thomas, $366 \mathrm{pp}$.

37) Taarnh $\phi$ j, P.: Decompression of the trigeminal root and the posterior part of the ganglion as treatment in trigeminal neuralgia. J. Neurosurg., 1952, 9: 288-290.

38) Walker, A. E.: The spinothalamic tract in man. Arch. Neurol. Psychiat, 1940, 43: 284-298.

39) Wetzel, N. and Biddle, A.: Cranial and cervical rhizotomy in the control of pain for malignancies of the head and neck. Arch. Surg., 1959, 79: 410-415.

40) White, J. C.: Modifications of frontal leucotomy for relief of pain and suffering in terminal malignant disease. In press, 1962.

41) White, J. C., Garrey, W. E. and Atkins, J. A.: Cardiac innervation: Experimental and clinical studies. Arch. Surg., 1933, 26: 765-786.

42) White, J. C., Richardson, E. P., Jr. and Sweet, W. H.: Upper thoracic cordotomy for relief of pain. Postmortem correlation of spinal incision with analgesic levels in 18 cases. Ann. Surg. 1956, 144: 407-420.

43) White, J. C., Smithwick, R. H. and Simeone, F. A.: The autonomic nervous system: Anatomy, physiology, and surgical application. 3rd edition. New York, Macmillan Co., 1952,569 pp.

44) White, J. C. and Sweet, W. H.: Pain: Its mechanisms and neurosurgical control. Springfield, Illinois, Charles C. Thomas, $1955,736 \mathrm{pp}$.

45) White, J. C., Sweet, W. H. and Hackett, T. P.: Radiofrequency leukotomy for relief of pain: Coagulation of medial frontal white fibers in stages by means of inlying electrodes. Arch. Neurol., 1960, 2: 317-330.

46) Womack, N. A. and Crider, R. L.: The persistence of symptoms following cholecystectomy. Ann. Surg., 1947, 126: 31-55. 